\title{
Pemetrexed in combination with cisplatin versus cisplatin monotherapy in East Asian patients with recurrent or metastatic head and neck cancer: Results of an exploratory subgroup analysis of a phase III trial
}

\author{
Susan URBA, ${ }^{1}$ Ruey-Long HONG, ${ }^{3}$ Anwar M HOSSAIN, ${ }^{2}$ Rebecca $\mathrm{CHENG}^{4}$ and \\ Mauro ORLANDO ${ }^{5}$ \\ ${ }^{1}$ University of Michigan Comprehensive Cancer Center, Division of Hematology/Oncology, Ann Arbor, Michigan, ${ }^{2}$ Eli Lilly \\ and Company, Indianapolis, Indiana, USA, ${ }^{3}$ Department of Oncology, National Taiwan University Hospital, ${ }^{4}$ Eli Lilly and \\ Company, Taipei, Taiwan and ${ }^{5}$ Eli Lilly Interamerica, Buenos Aires, Argentina
}

\begin{abstract}
Aim: An exploratory subgroup analysis of East Asian (EA) patients in a phase III trial was conducted to assess efficacy and safety trends based on ethnicity.

Methods: The 795 patients with recurrent or metastatic squamous cell carcinoma of the head and neck included 111 EA patients randomized to pemetrexed-cisplatin $(n=55)$ and placebo-cisplatin $(n=56)$ and 684 non- EA patients randomized to pemetrexed-cisplatin $(n=343)$ and placebo-cisplatin $(n=341)$. Treatment differences in median overall survival and progression-free survival were compared using a stratified log-rank test. Survival was estimated using the Kaplan-Meier method.

Results: The median overall survival in the pemetrexed-cisplatin and placebo-cisplatin arms of the EA group (6.8 and 5.7 months, respectively $[P=0.275])$ was similar to that in the global population $(7.3$ and 6.3 months, respectively $[P=0.082]$ ); the median progression-free survival in the pemetrexed-cisplatin and placebo-cisplatin arms in the EA group (2.8 and 1.9 months, respectively $[P=0.748])$ was similar to that in the global population (3.6 and 2.8 months, respectively $[P=0.166])$. Compared to the findings in the global population, overall survival for the EA group receiving prior platinum-based therapy was longer $(P=0.042$ vs $P=0.065)$. There was no significant interaction between treatment arms and ethnicity.

Conclusion: Consistent with findings in the global population, pemetrexed-cisplatin did not improve survival compared with placebo-cisplatin for the EA group. However, in a subgroup analysis, pemetrexedcisplatin showed an overall survival advantage in EA patients receiving prior platinum-based therapy.
\end{abstract}

Key words: cisplatin, clinical trial, phase III, head and neck neoplasm, pemetrexed.

\section{INTRODUCTION}

Squamous cell carcinoma of the head and neck $(\mathrm{SCCHN})-\mathrm{a}$ heterogeneous collection of epithelial

Correspondence: Dr Mauro Orlando MD, Eli Lilly

Interamerica, Tronador 4890, Piso 12, Buenos Aires

C1430D, Argentina. Email: mauro@lilly.com

Conflict of interest: $\mathrm{AMH}, \mathrm{RC}$, and MO are employees of, and own stock in, Eli Lilly and Company. SU was paid to travel to study sites by Eli Lilly and Company. RH declares no conflict of interest.

Accepted for publication 10 December 2012. malignancies arising in the upper aerodigestive tract is the sixth most common cancer worldwide and accounts for an estimated 650000 new cases and 350000 deaths every year. ${ }^{1,2}$ Because patients with recurrent and metastatic SCCHN are generally incurable, treatment goals are the prolongation of overall survival (OS) or progression-free survival (PFS), the palliation of existing symptoms and the prevention of new cancer-related symptoms. ${ }^{3,4}$

Among the multiple chemotherapeutic agents that induce tumor responses, cisplatin is frequently used to treat patients with inoperable recurrent or metastatic 
SCCHN, either as a monotherapy or in combination with other chemotherapeutic agents. ${ }^{4,5}$ The median survival with cisplatin combination chemotherapy ranges from approximately 8 to 9 months, with a corresponding 1 -year survival rate of approximately 30 to 40 percent. ${ }^{67}$ Pemetrexed, an inhibitor of thymidylate synthase and other folate-dependent enzymes ${ }^{8-10}$ has been investigated in patients with SCCHN ${ }^{11,12}$ and other solid tumors. ${ }^{13-17}$ In a Phase III trial in patients with SCCHN, pemetrexed-cisplatin showed OS and PFS advantages in the subset of patients with Eastern Cooperative Oncology Group (ECOG) performance status (PS) 0 or 1 or oropharyngeal cancer. ${ }^{12}$

Ethnic minorities (South Asian and Chinese groups) in British Columbia are at higher risk for both oropharyngeal cancer and oral cavity cancer among men and oral cavity cancer among women. ${ }^{18}$ The pathogenesis of SCCHN in some Asian countries is somewhat different from that in other areas of the world; it is known to be related to betel quid chewing, which is considered a poor prognostic factor. ${ }^{19,20}$ In a cohort analysis, the increase in the incidence of oropharyngeal cancer in Taiwan was proposed to be heavily influenced by the increase in the consumption of alcohol and the use of betel quid. ${ }^{21}$ Due to the unique pathogenesis of SCCHN in some Asian countries, the aim of this exploratory analysis of an East Asian (EA) patient group in a global phase III trial was to assess possible trends in efficacy or safety based on ethnicity.

\section{METHODS}

\section{Study design and treatment plan}

We performed an exploratory analysis of the randomized, double-blind, placebo-controlled, phase III, global trial reported by Urba et al. ${ }^{12}$ In this trial, 795 patients with recurrent or metastatic SCCHN and no prior systemic therapy for metastatic disease were enrolled and randomly assigned to pemetrexed plus cisplatin (pemetrexed-cisplatin; $n=398$ ) or placebo plus cisplatin (placebo-cisplatin; $n=397$ ). ${ }^{12}$ Patients received pemetrexed $500 \mathrm{mg} / \mathrm{m}^{2}$ (10-min infusion) plus cisplatin $75 \mathrm{mg} / \mathrm{m}^{2}$ or placebo (100 mL saline) plus cisplatin $75 \mathrm{mg} / \mathrm{m}^{2}$ on day 1 every 21 days thereafter. Chemotherapy was administered for six cycles; patients could be discontinued from the study before the completion of the six cycles for disease progression, unacceptable toxicity, or the decision of patient or physician, or both. Additional cycles were permitted for patients showing a benefit from the study treatment. All patients were followed up until death or the closure of the study. Details on the study design and treatment were described previously. ${ }^{12}$ Only patients enrolled in China, Korea and Taiwan were considered EA $(n=111,14 \%)$ and were included in the subgroup analysis reported here. The non-EA group included a total of 684 patients (pemetrexed-cisplatin, $n=343$ and placebo-cisplatin, $n=341)$.

The original trial ${ }^{12}$ was conducted according to the Declaration of Helsinki and good clinical practice guidelines and was approved by each participating institutional and its ethical review board. All patients signed a written informed consent from before treatment.

\section{Baseline and treatment assessments}

Details of the tumor assessments have been previously reported. ${ }^{12}$ Palpable tumors were measured within 2 weeks of the first treatment. For each patient the imaging method used at baseline was also used for each assessment throughout the study. Tumor assessments were repeated every other cycle and every 6 weeks after treatment discontinuation until disease progression. Patients who had baseline imaging and at least one scan after starting chemotherapy were considered assessable for tumor response using response evaluation criteria in solid tumors 1.0. ${ }^{22}$ OS and PFS analyses incorporated all randomized patients on an intent to treat (ITT) basis.

Patients were assessed for toxicity before each cycle according to the common terminology criteria for adverse events, vers. 3.0. ${ }^{23}$ All patients who received at least one dose of pemetrexed or cisplatin were considered assessable for safety. ${ }^{12}$

\section{Statistical analyses}

In the original trial, ${ }^{12}$ the primary efficacy measure was OS. Secondary end-points included PFS, tumor response rate and safety assessment. ${ }^{12}$ In this report OS, PFS, tumor response rate and toxicities between treatment arms in the EA group were compared. In addition, analyses of the selected subgroups, including stratification factors in the EA group, were also performed. The analyses in the EA group used the same methodology as was used in the global population. ${ }^{12}$ The analyses for this study are underpowered due to the small sample size; therefore, the data are considered exploratory. Due to the exploratory nature of the analyses, the $P$-values were not adjusted for multiplicity.

To compare the time-to-event end-points (including the primary end-point, OS), a stratified log-rank test at a two-sided $\alpha=0.05$ was used, with the following prognostic factors as stratification variables: ECOG PS (0/1 
vs 2), previously treated for SCCHN (no $v s$ yes), distant metastasis (no $v s$ yes) and prior platinum-based therapy (no vs yes). The Kaplan-Meier method was used to estimate survival distributions. ${ }^{24}$ To obtain treatment effect after adjusting for the prognostic variables, supportive analyses were conducted using the Cox regression model..$^{25}$ All efficacy analyses were performed on ITT patients in the EA group. Patients who had at least one dose of study treatment were included in the safety analyses.

Exploratory subgroup analyses for OS and PFS were conducted on selected subgroups of EA patients: ECOG PS (0/1 vs 2), previously treated SCCHN (no vs yes), prior platinum-based therapy (no $v s$ yes), distant metastasis (no $v s$ yes), age ( $<65 v s \geq 65$ years), sex (male $v s$ female), primary site of disease (oral cavity, oropharynx, hypopharynx, larynx, and other) and prior surgery or radiotherapy within 6 months of randomization (no $v s$ yes). These stratification factors are considered to be potential prognostic factors; therefore, the randomization was done with these stratification factors to ensure balance in treatment allocation. An unstratified log-rank test was used to assess the treatment difference within subgroups and the Cox regression model was used to test the treatment-by-subgroup interaction. Tumor responses were compared between treatments using unadjusted normal approximation for differences in rates. The incidences of toxicities were analyzed using Fisher's exact test.

\section{RESULTS}

\section{Patients and treatment}

Of the 795 patients randomized to pemetrexed-cisplatin $(n=398)$ or placebo-cisplatin $(n=397),{ }^{12} 111$ EA patients (14\% [China, $n=12$; Korea, $n=53$; Taiwan, $n=46$; pemetrexed-cisplatin, $n=55$; placebo-cisplatin, $n=56$ ) were included in the subgroup analyses reported here. The non-EA group included a total of 684 patients (pemetrexed-cisplatin, $n=343$; placebocisplatin, $n=341$ ). Among EA patients the patients' baseline characteristics, disease characteristics, and disease sites were comparable between treatment arms (Table 1). These data are similar to those reported for the global population; ${ }^{12}$ therefore, the EA group is representative of the global population. There were some differences in patients' characteristics between the EA group and the non-EA group with respect to sex, previous treatment for SCCHN, prior platinum-based therapy, and oral cavity as the primary site of disease (Table 1). In the EA group, 49 percent of patients in the pemetrexed-cisplatin arm and 36 percent of patients in the placebo-cisplatin arm received prior platinum-based therapy; in the non-EA group, 46 percent of patients in the pemetrexed-cisplatin arm and 44 percent of patients in the placebo-cisplatin arm received prior platinumbased therapy. In the global population, 47 percent of patients in the pemetrexed-cisplatin arm received prior platinum-based therapy compared with 43 percent of patients in the placebo-cisplatin arm. ${ }^{12}$ The oral cavity was the primary site of disease in both treatment arms in the EA group (pemetrexed-cisplatin, 49\%; placebo-cisplatin, $43 \%$ ) and the global population (pemetrexed-cisplatin, 35\% ; placebo-cisplatin, 31\%). ${ }^{12}$

\section{Efficacy}

The analysis of the primary end-point, OS, was conducted for the EA group. The OS for patients in the pemetrexed-cisplatin arm was not significantly different relative to patients in the placebo-cisplatin arm (Fig. 1a). The median OS times were 6.8 and 5.7 months for the pemetrexed-cisplatin and placebo-cisplatin arms, respectively (hazard ratio $[\mathrm{HR}]=0.85 ; 95 \%$ confidence interval $[\mathrm{CI}]=0.56-1.30 ; P=0.275$ ) (Fig. 1a). These were similar to the median OS times in the global population pemetrexed-cisplatin (7.3 months) and placebocisplatin (6.3 months) arms $(P=0.082){ }^{12}$

An analysis of PFS, a secondary end-point, was also conducted for the EA group. The median PFS times in the EA group were 2.8 and 1.9 months for the pemetrexedcisplatin and placebo-cisplatin arms, respectively $(\mathrm{HR}=$ $0.89 ; 95 \%$ CI $=0.59-1.35 ; P=0.748$ ) (Fig. 1b). The median PFS times in the global population were 3.6 and 2.8 months for the pemetrexed-cisplatin and placebocisplatin arms, respectively $(P=0.166){ }^{12}$

Exploratory subgroup analyses showed that, among EA patients with an ECOG PS of 0 or 1, the median OS was 8.2 months for patients in the pemetrexedcisplatin arm and 6.3 months for patients in the placebo-cisplatin arm $(\mathrm{HR}=0.78 ; 95 \% \mathrm{CI}=0.48-1.26$; $P=0.302$ ) (Fig. 1c, Table 2). However, in the global population, ECOG PS of 0 or 1 patients treated with pemetrexed-cisplatin led to a significantly longer median OS (8.4 months) than patients treated with placebocisplatin (6.7 months) $(\mathrm{HR}=0.83 ; 95 \% \mathrm{CI}=0.70$ 0.98; $P=0.026) .{ }^{12}$ The EA patients with ECOG PS 2 had a median OS of 3.7 months in the pemetrexedcisplatin arm and 4.7 months in the placebo-cisplatin $\operatorname{arm}(P=0.688)$ (Table 2). Similarly, in the global population, the ECOG PS 2 subgroup had a median OS of 3.5 months in the pemetrexed-cisplatin arm and 3.3 months in the placebo-cisplatin arm $(P=0.243) .{ }^{12}$ 
Table 1 Baseline and disease characteristics of the East Asian and non-East Asian group

\begin{tabular}{|c|c|c|c|c|}
\hline \multirow[b]{2}{*}{ Characteristic } & \multicolumn{2}{|c|}{ East Asian } & \multicolumn{2}{|c|}{ Non-East Asian } \\
\hline & $\begin{array}{l}\text { Pem-cis } \\
(n=55)\end{array}$ & $\begin{array}{c}\text { Placebo-cis } \\
\quad(n=56)\end{array}$ & $\begin{array}{l}\text { Pem-cis } \\
(n=343)\end{array}$ & $\begin{array}{c}\text { Placebo-cis } \\
(n=341)\end{array}$ \\
\hline \multicolumn{5}{|l|}{ Age, years } \\
\hline Median & 54.4 & 57.6 & 57.7 & 57.9 \\
\hline Range & $37-76$ & $33-72$ & $32-79$ & $21-84$ \\
\hline \multicolumn{5}{|l|}{ Sex, $n(\%)$} \\
\hline Male & $51(93)$ & $53(95)$ & $291(85)$ & $291(85)$ \\
\hline Female & $4(7)$ & $3(5)$ & $52(15)$ & $50(14.7)$ \\
\hline \multicolumn{5}{|l|}{ Ethnicity, $n(\%)$} \\
\hline African & $0(0)$. & $0(0)$ & $17(5)$ & $12(3.5)$ \\
\hline Caucasian & $0(0)$ & $0(0)$ & $243(71)$ & $233(68)$ \\
\hline East Asian & $53(96)$ & $56(100)$ & $2(0.6)$ & $9(3)$ \\
\hline Hispanic & $0(0)$ & $0(0)$ & $11(3)$ & $16(5)$ \\
\hline Indian & $2(4)$ & $0(0)$ & $70(20)$ & $70(21)$ \\
\hline \multicolumn{5}{|l|}{ ECOG PS, $n(\%)$} \\
\hline 0 or 1 & $45(82)$ & $46(82)$ & $302(88)$ & $297(87)$ \\
\hline 2 & $10(18)$ & $10(18)$ & $41(12)$ & $43(13)$ \\
\hline \multicolumn{5}{|c|}{ Previously treated for HNC, $n(\%)$} \\
\hline Yes & $48(87)$ & $46(82)$ & $315(92)$ & $312(92)$ \\
\hline No & $7(13)$ & $10(18)$ & $28(8)$ & $29(9)$ \\
\hline \multicolumn{5}{|c|}{ Prior platinum-based therapy, $n(\%)$} \\
\hline Yes & $27(49)$ & $20(36)$ & $158(46)$ & $149(44)$ \\
\hline No & $28(51)$ & $36(64)$ & $185(54)$ & $192(56)$ \\
\hline \multicolumn{5}{|c|}{ Distant metastasis, $n(\%)$} \\
\hline Yes & $34(62)$ & $33(59)$ & $199(58)$ & $209(61)$ \\
\hline No & $21(38)$ & $23(41)$ & $144(42)$ & $132(39)$ \\
\hline \multicolumn{5}{|c|}{ Primary site of disease, $n(\%)$} \\
\hline Oral cavity & $27(49)$ & $24(43)$ & $111(32)$ & $99(29)$ \\
\hline Larynx & $11(20)$ & $13(23)$ & $92(27)$ & $89(26)$ \\
\hline Oropharynx & $10(18)$ & $6(11)$ & $76(22)$ & $100(29)$ \\
\hline Hypopharynx & $7(13)$ & $10(18)$ & $56(16)$ & $49(14)$ \\
\hline Other & $0(0)$ & $3(5)$ & $8(2)$ & $4(1)$ \\
\hline
\end{tabular}

Cis, cisplatin; ECOG, Eastern Cooperative Oncology Group; HNC, head and neck cancer; $n$, number of patients in group; pem, pemetrexed; PS, performance status.

Among EA patients with an ECOG PS of 0 or 1 , the median PFS was 2.9 months for patients in the pemetrexed-cisplatin arm and 2.6 months for patients in the placebo-cisplatin arm $(\mathrm{HR}=0.91 ; 95 \% \mathrm{CI}=$ $0.6-1.4 ; P=0.688$ ) (Fig. $1 \mathrm{~d}$ ). In contrast, in the global population, in patients with an ECOG PS 0 or 1, pemetrexed-cisplatin led to significantly longer PFS than placebo-cisplatin $(P=0.044) .{ }^{12}$ Among EA patients with ECOG PS 2, the median PFS was 1.5 months for the pemetrexed-cisplatin arm and 1.4 months for the placebo-cisplatin arm $(P=0.565)$. In the global population, the ECOG PS 2 subgroup had a median PFS of 1.6 months for the pemetrexed-cisplatin arm and 1.8 months for the placebo-cisplatin arm $(P=0.070)$.
In the subgroup of EA patients who received prior platinum-based therapy, the median OS was 4.8 months longer in the pemetrexed-cisplatin arm than in the placebo-cisplatin arm (10.3 months vs 5.5 months, respectively $) \quad(\mathrm{HR}=0.49 ; 95 \% \quad \mathrm{CI}=0.24-0.99 ; \quad P=$ 0.042) (Table 2). However, in the subgroup of the global population receiving prior platinum-based therapy, the between-group difference in median OS was not significant (pemetrexed-cisplatin, 7.5 months; placebocisplatin, 6.6 months; $\mathrm{HR}=0.80 ; 95 \% \mathrm{CI}=0.63-1.01$; $P=0.065)$.

In preplanned subgroup analyses involving all EA patients and EA patients in the PS 0 or 1 subgroup, OS and PFS seem to favor pemetrexed-cisplatin over 

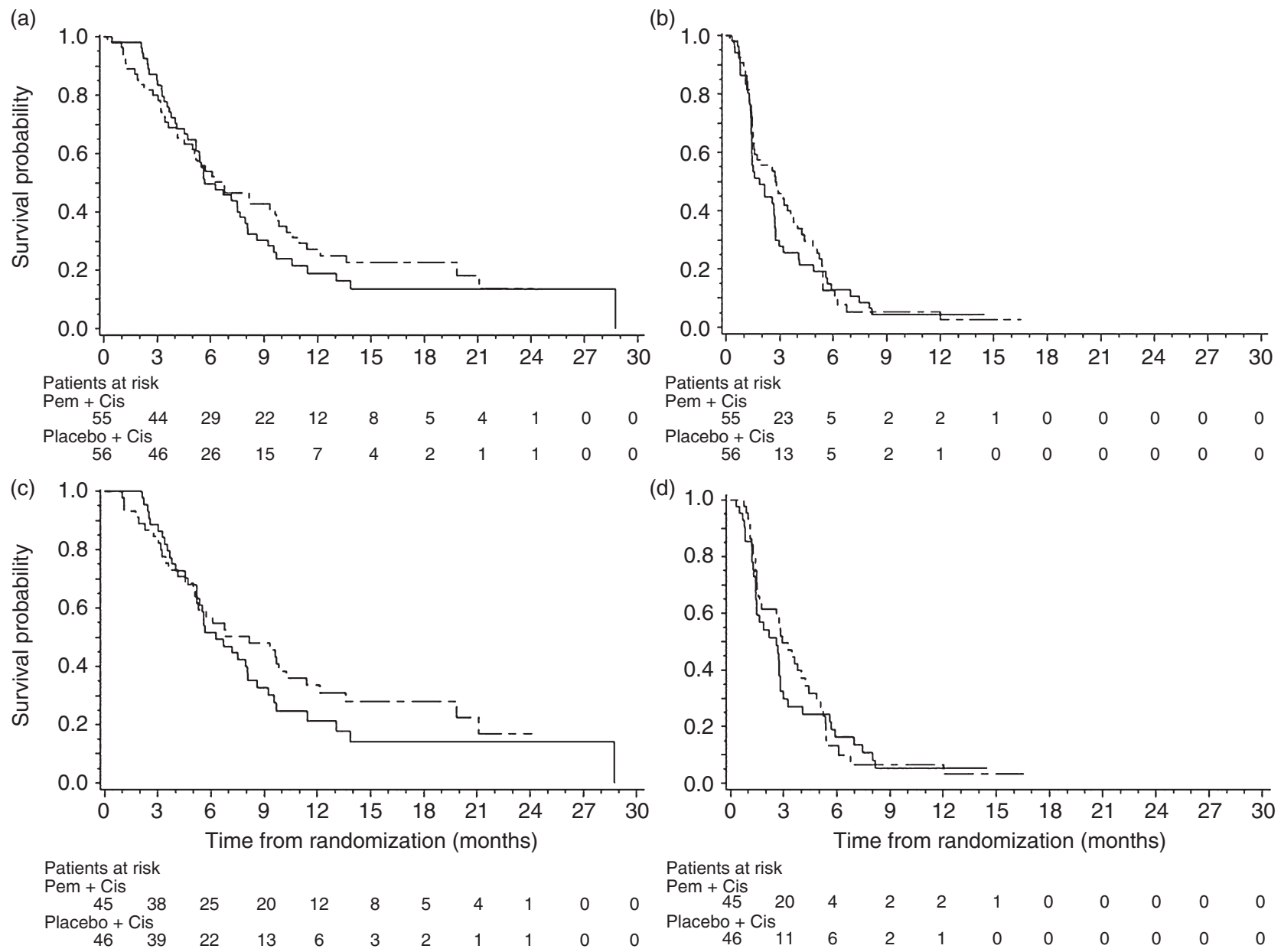

Figure 1 Kaplan-Meier plots of overall survival (OS) and progression-free survival (PFS) for East Asian group and Eastern Cooperative Oncology Group performance status (PS) 0 or 1 subgroup showing (a) OS; (b) PFS; (c) OS for group with performance status 0 or 1; and (d) PFS for group with PS 0 or 1. Cis, cisplatin; Pem, pemetrexed. . -, placebo + cis; - - pem + cis.

placebo-cisplatin across most of the groups (all HR $<1.00$ ) (Tables 3 and 4).

The objective response rate in the EA group was 15 percent in the pemetrexed-cisplatin arm compared with 11 percent in the placebo-cisplatin arm $(P=0.543)$; all were partial responses. Stable disease rate in the EA group was 29 percent in the pemetrexed-cisplatin arm compared with 18 percent in the placebo-cisplatin arm; progressive disease rate was 38 percent in the pemetrexed-cisplatin arm compared with 55 percent in the placebo-cisplatin arm. Similarly, the objective response rate in the non-EA group was 12 percent in the pemetrexed-cisplatin arm compared with 8 percent in the placebo-cisplatin arm $(P=0.074)$. The stable disease rate in the non-EA group was 40 percent in the pemetrexed-cisplatin arm compared with 36.7 percent in the placebo-cisplatin arm, and the progressive disease rate was 11 versus 7 percent, respectively. Likewise, in the global population, the tumor response rate (complete response and partial response) was not significantly different between treatment arms (pemetrexed-cisplatin, 12\%; placebocisplatin, $8 \% ; P=0.061) .{ }^{12}$

The Cox regression analysis showed that the prognostic factor of an ECOG PS of 0 or 1 had a significant effect on OS (PS 0 or 1 vs PS 2; $\mathrm{HR}=0.43$; 95\% $\mathrm{CI}=0.25-0.74 ; P=0.002$ ) and PFS (PS 0 or 1 vs PS 2; $\mathrm{HR}=0.56 ; 95 \% \mathrm{CI}=0.33-0.93 ; P=0.025)$. In addition, significant prognostic effects on OS were demonstrated in subgroups previously treated for SCCHN (not treated for SCCHN vs treated; HR $=0.49 ; 95 \%$ $\mathrm{CI}=0.26-0.95 ; P=0.034$.) and prior platinum-based 
Table 2 Analyses of overall survival for the subgroup of East Asian patients (ITT population)

\begin{tabular}{|c|c|c|c|c|c|c|}
\hline \multirow[b]{2}{*}{ Subgroup } & \multicolumn{2}{|c|}{ Pem-cis $(n=55)$} & \multicolumn{2}{|c|}{ Placebo-cis $(n=56)$} & \multirow[b]{2}{*}{$P$-value } & \multirow[b]{2}{*}{$\operatorname{HR}(95 \% \mathrm{CI})$} \\
\hline & $n(\%)$ & $\begin{array}{c}\text { Median OS } \\
\text { (months) }\end{array}$ & $n(\%)$ & $\begin{array}{c}\text { Median OS } \\
\text { (months) }\end{array}$ & & \\
\hline \multicolumn{7}{|c|}{ ECOG performance status } \\
\hline 0 or 1 & $45(82)$ & 8.2 & $46(82)$ & 6.3 & 0.302 & $0.78(0.48-1.26)$ \\
\hline 2 & $10(18)$ & 3.7 & $10(18)$ & 4.7 & 0.688 & $1.21(0.48-3.00)$ \\
\hline \multicolumn{7}{|c|}{ Previously treated for HNC } \\
\hline Yes & $48(87)$ & 6.8 & $46(82)$ & 5.5 & 0.149 & $0.71(0.44-1.13)$ \\
\hline No & $7(13)$ & 3.4 & $10(18)$ & 9.6 & 0.385 & $1.62(0.54-4.89)$ \\
\hline \multicolumn{7}{|c|}{ Distant metastasis } \\
\hline Yes & $34(62)$ & 5.1 & $33(59)$ & 5.7 & 0.917 & $0.97(0.57-1.66)$ \\
\hline No & $21(38)$ & 9.8 & $23(41)$ & 5.9 & 0.226 & $0.64(0.31-1.32)$ \\
\hline \multicolumn{7}{|c|}{ Prior platinum-based therapy } \\
\hline Yes & $27(49)$ & 10.3 & $20(36)$ & 5.5 & 0.042 & $0.49(0.24-0.99)$ \\
\hline No & $28(51)$ & 4.8 & $36(64)$ & 7.5 & 0.485 & $1.21(0.70-2.10)$ \\
\hline
\end{tabular}

CI, confidence interval; Cis, cisplatin; ECOG, Eastern Cooperative Oncology Group; HNC, head and neck cancer; HR, hazard ratio of pem + cis over placebo + cis; ITT, intent to treat; $n$, number of patients in group; OS, overall survival; Pem, pemetrexed.

therapy (not treated with platinum $v s$ treated; $\mathrm{HR}=1.69 ; \quad 95 \% \quad \mathrm{CI}=1.03-2.78 ; \quad P=0.038$. It is important to note that the subset analyses of the EA group are underpowered.

The median OS times for the non-EA group were 7.4 and 6.3 months for the pemetrexed-cisplatin and placebo-cisplatin arms, respectively. The median PFS times for the non-EA group were 3.9 months and 3.1 month for the pemetrexed-cisplatin and placebocisplatin arm, respectively. Subgroup analyses of the EA group (pemetrexed-cisplatin, $n=55$; placebo-cisplatin, $n=56$ ) versus the non-EA group (pemetrexed-cisplatin, $n=343$; placebo-cisplatin, $n=341$ ) showed no significant interactions between both treatment arms or between the EA versus non-EA groups in the OS outcome (interaction $P=0.817$ ) or the PFS outcome (interaction $P=0.984$ ). In other words, the pemetrexedcisplatin benefits in OS and PFS in the EA and non-EA groups subgroups were similar.

More EA patients discontinued treatment in the placebo-cisplatin arm due to progressive disease (38 [68\%]) compared with those in the pemetrexed-cisplatin $\operatorname{arm}(29[53 \%])$.

\section{Post-discontinuation therapy}

In the EA group, $37(66 \%)$ patients in the placebocisplatin arm received systemic post-discontinuation therapy, whereas $27(49 \%)$ patients in the pemetrexedcisplatin arm received systemic post-discontinuation therapy.

\section{Safety}

In the EA group, drug-related grade 3 or 4 laboratory toxicities in the pemetrexed-cisplatin arm compared with the placebo-cisplatin arm included neutropenia (11 vs 2\%), anemia (6 vs 2\%) and thrombocytopenia (4 vs 12\%); drug-related grade 3 or 4 non-laboratory toxicity in the pemetrexed-cisplatin arm compared with the placebo-cisplatin arm included nausea (4 vs 2\%). None of the between-group differences were significant (Table 5).

In the non-EA group, drug-related grade 3 or 4 laboratory toxicities in the pemetrexed-cisplatin arm compared with the placebo-cisplatin arm included neutropenia (12 vs 3\%), anemia (11 vs 4\%), leukopenia (10 vs $1 \%$ ) and thrombocytopenia (4 vs $2 \%$ ) (Table 5). The between-group differences for neutropenia, anemia and leukopenia were significant. In the non-EA group, drug-related grade 3 or 4 non-laboratory toxicities the pemetrexed-cisplatin arm compared with the placebocisplatin arm included fatigue (6vs $2 \% ; P=0.026)$ and febrile neutropenia ( $3 v s 0 \% ; P=0.001)$. In the global population, patients in the pemetrexed-cisplatin arm exhibited a significantly higher incidence of drug-related grade 3 or 4 laboratory toxicities and drug-related grade 3 or 4 non-laboratory toxicities compared with those in the placebo-cisplatin arm. ${ }^{12}$

In the EA group, $10(19 \%)$ patients in the pemetrexed-cisplatin arm and four $(8 \%)$ patients in the placebo-cisplatin arm died during therapy or within 30 days of treatment discontinuation. In the global 
Table 3 Subgroup analyses of overall survival for East Asian patients with Eastern Cooperative Oncology Group performance status of 0 or 1

\begin{tabular}{|c|c|c|c|c|c|c|}
\hline \multirow[b]{2}{*}{ Subgroup } & \multicolumn{2}{|c|}{ Pem-cis $(n=45)$} & \multicolumn{2}{|c|}{ Placebo-cis $(n=46)$} & \multirow[b]{2}{*}{$P$-value } & \multirow[b]{2}{*}{$\operatorname{HR}(95 \% \mathrm{CI})$} \\
\hline & $n(\%)$ & $\begin{array}{l}\text { Median OS } \\
\text { (months) }\end{array}$ & $n(\%)$ & $\begin{array}{c}\text { Median OS } \\
\text { (months) }\end{array}$ & & \\
\hline \multicolumn{7}{|c|}{ Previously treated for head and neck cancer } \\
\hline Yes & $39(87)$ & 8.2 & $40(87)$ & 5.6 & 0.101 & $0.65(0.4-1.1)$ \\
\hline No & $6(13)$ & 6.4 & $6(13)$ & 11.4 & 0.329 & $1.92(0.5-7.2)$ \\
\hline \multicolumn{7}{|l|}{ Distant metastasis } \\
\hline Yes & $28(62)$ & 5.5 & $25(54)$ & 8.0 & 0.945 & $0.98(0.5-1.8)$ \\
\hline No & $17(38)$ & 9.8 & $21(46)$ & 5.6 & 0.086 & $0.50(0.2-1.1)$ \\
\hline \multicolumn{7}{|c|}{ Prior platinum-based therapy } \\
\hline Yes & $19(42)$ & 11.4 & $17(37)$ & 5.5 & 0.011 & $0.34(0.1-0.8)$ \\
\hline No & $26(58)$ & 5.0 & $29(63)$ & 8.0 & 0.497 & $1.23(0.7-2.2)$ \\
\hline \multicolumn{7}{|c|}{$\begin{array}{l}\text { Prior surgery or radiotherapy within } \\
6 \text { months of randomization }\end{array}$} \\
\hline Yes & $10(22)$ & 9.8 & $9(20)$ & 5.2 & 0.145 & $0.44(0.1-1.4)$ \\
\hline No & $35(78)$ & 6.8 & $37(80)$ & 7.2 & 0.687 & $0.90(0.5-1.5)$ \\
\hline \multicolumn{7}{|c|}{ Primary site of disease } \\
\hline Oral cavity & $22(49)$ & 8.9 & $23(50)$ & 5.3 & 0.109 & $0.57(0.3-1.1)$ \\
\hline Larynx & $10(22)$ & 6.8 & $10(22)$ & 8.1 & 0.804 & $1.15(0.4-3.5)$ \\
\hline Oropharynx & $9(20)$ & 9.7 & $3(7)$ & 9.6 & 0.443 & $0.57(0.1-2.4)$ \\
\hline Hypopharynx & $4(9)$ & 2.5 & $8(17)$ & 9.2 & $0.003^{\dagger}$ & $14.13(1.5-129.5)$ \\
\hline Other & NA & NA & $2(4)$ & 2.9 & NA & NA \\
\hline \multicolumn{7}{|l|}{ Age } \\
\hline$<65$ & $33(73.3)$ & 9.7 & $39(85)$ & 6.7 & 0.18 & $0.69(0.4-1.2)$ \\
\hline$\geq 65$ & $12(26.7)$ & 5.0 & $7(15)$ & 5.7 & 0.612 & $1.31(0.5-3.7)$ \\
\hline \multicolumn{7}{|l|}{ Sex } \\
\hline Male & $41(91.1)$ & 8.2 & $44(96)$ & 6.3 & 0.261 & $0.75(0.5-1.2)$ \\
\hline Female & $4(8.9)$ & 8.3 & $2(4)$ & . & $0.896^{\dagger}$ & $1.17(0.1-11.4)$ \\
\hline \multicolumn{7}{|l|}{ Race } \\
\hline Non-Caucasian & $45(100.0)$ & 8.2 & $46(100.0)$ & 6.3 & 0.302 & $0.78(0.5-1.3)$ \\
\hline
\end{tabular}

${ }^{\dagger} P$-value should be interpreted with caution as the sample size is very small. CI, confidence interval; cis, cisplatin; HR, hazard ratio of pem + cis over placebo + cis; $n$, number of patients in group; NA, not assessable; OS, overall survival; pem, pemetrexed.

population, $92(24 \%)$ patients in the pemetrexedcisplatin arm and $96(25 \%)$ patients in the placebocisplatin arm died during therapy or within 30 days of treatment discontinuation. ${ }^{12}$ One $(2 \%)$ patient in the pemetrexed-cisplatin arm in the EA group died due to study drug toxicity (acute renal failure/sepsis).

\section{DISCUSSION}

This is an exploratory subgroup analysis involving the EA group in the recently reported phase III, randomized, double-blind trial comparing pemetrexed-cisplatin to placebo-cisplatin in patients with inoperable recurrent or metastatic SCCHN. ${ }^{12}$ As observed in the global study population, patients in the pemetrexed-cisplatin arm did not show significant improvements in OS and PFS com- pared with patients on cisplatin monotherapy in the EA group. However, the between-arm differences in OS and PFS in the EA group were similar to those reported in the global population, suggesting there was no impact from ethnicity on the study results.

Overall, the tumor response rate (complete response and partial response) results were consistent across the EA and global populations. ${ }^{12}$ Similarly, the tumor response rates in the EA and non-EA groups were similar. In a more restricted analysis confined to the group with an ECOG PS of 0 or 1, which comprised 82 percent of EA patients, pemetrexed-cisplatin treatment was associated with improved OS compared with placebo-cisplatin. This improvement in OS was not statistically significant compared with placebo-cisplatin; however, the between-arm differences in OS and PFS 
Table 4 Subgroup analyses of progression-free survival for East Asian patients with Eastern Cooperative Oncology Group performance status of 0 or 1

\begin{tabular}{|c|c|c|c|c|c|c|}
\hline \multirow[b]{2}{*}{ Subgroup } & \multicolumn{2}{|c|}{ Pem-cis $(n=45)$} & \multicolumn{2}{|c|}{ Placebo-cis $(n=46)$} & \multirow[b]{2}{*}{$P$-value } & \multirow[b]{2}{*}{$\operatorname{HR}(95 \% \mathrm{CI})$} \\
\hline & $n(\%)$ & $\begin{array}{c}\text { Median PFS } \\
\text { (months) }\end{array}$ & $n(\%)$ & $\begin{array}{c}\text { Median PFS } \\
\text { (months) }\end{array}$ & & \\
\hline \multicolumn{7}{|c|}{ Previously treated for head and neck cancer } \\
\hline Yes & $39(87)$ & 2.9 & $40(87)$ & 2.7 & 0.633 & $0.88(0.5-1.5)$ \\
\hline No & $6(13)$ & 2.4 & $6(13)$ & 1.5 & 0.886 & $1.10(0.3-3.9)$ \\
\hline \multicolumn{7}{|l|}{ Distant metastasis } \\
\hline Yes & $28(62)$ & 2.8 & $25(54)$ & 1.9 & 0.756 & $0.91(0.5-1.7)$ \\
\hline No & $17(38)$ & 3.6 & $21(46)$ & 2.7 & 0.791 & $0.91(0.4-1.9)$ \\
\hline \multicolumn{7}{|c|}{ Prior platinum-based therapy } \\
\hline Yes & $19(42)$ & 3.8 & $17(37)$ & 2.7 & 0.401 & $0.72(0.3-1.6)$ \\
\hline No & $26(58)$ & 2.9 & $29(63)$ & 1.6 & 0.875 & $1.05(0.6-1.9)$ \\
\hline \multicolumn{7}{|c|}{$\begin{array}{l}\text { Prior surgery or radiotherapy within } \\
6 \text { months of randomization }\end{array}$} \\
\hline Yes & $10(22)$ & 2.9 & $9(20)$ & 1.2 & 0.994 & $1.00(0.4-2.8)$ \\
\hline No & $35(78)$ & 3.2 & $37(80)$ & 2.7 & 0.611 & $0.87(0.5-1.5)$ \\
\hline \multicolumn{7}{|c|}{ Primary site of disease } \\
\hline Oral cavity & $22(49)$ & 2.8 & $23(50)$ & 2.4 & 0.255 & $0.70(0.4-1.3)$ \\
\hline Larynx & $10(22)$ & 4.2 & $10(22)$ & 5.7 & 0.268 & $2.16(0.5-8.7)$ \\
\hline Oropharynx & $9(20)$ & 4.9 & $3(7)$ & 4.4 & 0.654 & $1.62(0.2-13.7)$ \\
\hline Hypopharynx & $4(8.9)$ & 1.2 & $8(17)$ & 2.2 & $0.015^{\dagger}$ & $7.38(1.2-44.5)$ \\
\hline Other & NA & NA & $2(4)$ & 1.5 & NA & NA \\
\hline \multicolumn{7}{|l|}{ Age (years) } \\
\hline$<65$ & $33(73)$ & 3.6 & $39(89)$ & 1.6 & 0.324 & $0.77(0.5-1.3)$ \\
\hline$\geq 65$ & $12(27)$ & 1.6 & $7(15)$ & 2.7 & 0.199 & $2.12(0.7-6.8)$ \\
\hline \multicolumn{7}{|l|}{ Sex } \\
\hline Male & $41(91)$ & 2.9 & $44(96)$ & 2.7 & 0.972 & $0.99(0.6-1.6)$ \\
\hline Female & $4(9)$ & 3.4 & $2(4)$ & 1.7 & $0.107^{\dagger}$ & $0.17(0.0-1.9)$ \\
\hline \multicolumn{7}{|l|}{ Race } \\
\hline Non-Caucasian & $45(100)$ & 2.9 & $46(100)$ & 2.6 & 0.688 & $0.91(0.6-1.4)$ \\
\hline
\end{tabular}

${ }^{\dagger} P$-value should be interpreted with caution as the sample size is very small. CI, confidence interval; cis, cisplatin; HR, hazard ratio of pem + cis over placebo + cis; $n$, number of patients in group; NA, not assessable; pem, pemetrexed; PFS, progression-free survival.

were statistically significant in patients in the global population with an ECOG PS of 0 or $1 .^{12}$ It is possible that the sample size of the EA group was not large enough to achieve statistical significance.

In the subgroup analyses, in EA patients with an ECOG PS of 0 or 1 , there was no significant difference in OS and PFS between the pemetrexed-cisplatin and placebo-cisplatin arms $(P=0.302$ and $P=0.688$, respectively); in contrast, in patients with an ECOG PS of 0 or 1 in the global population, pemetrexedcisplatin or placebo-cisplatin led to significantly longer OS $(P=0.026)$ and PFS $(P=0.044)$ than placebocisplatin. ${ }^{12}$ It is important to note that these findings could be due to the relatively small sample size of the EA group and the exploratory nature of the analysis.

In the subgroup analysis involving EA patients with an ECOG PS of 0 or 1, as expected, the median OS in patients with PS 0 or 1 in the pemetrexed-cisplatin arm (8.2 months) versus that for patients in the placebocisplatin arm (6.3 months) contrasts with the median OS in patients with PS 2 receiving the same treatments $(3.7$ months vs 4.7 months, respectively).

The Cox regression analysis showed that an ECOG PS of 0 or 1 had a significant and perhaps clinically relevant effect on OS $(P=0.002)$ and PFS $(P=0.025)$, confirming that an ECOG PS of 0 or 1 was a prognostic factor in this study. These results emphasize that the benefit of pemetrexed plus cisplatin in the EA group with advanced SCCHN is primarily observed in patients with a good ECOG PS (0 or 1$)$. It is also important to note that the relatively low number of patients with ECOG PS $2(18 \%$ of the EA patients) may have negatively impacted on the results in the EA group. These results are consistent with those obtained in the global population. ${ }^{12}$ 
Table 5 Patients with selected Common Terminology Criteria for Adverse Events grade 3 or 4 drug-related toxicities (worst grade) in East Asian and non-East Asian groups ${ }^{\dagger}$

\begin{tabular}{|c|c|c|c|c|c|c|}
\hline \multirow[b]{2}{*}{ Toxicity } & \multicolumn{3}{|c|}{ East Asian } & \multicolumn{3}{|c|}{ Non-East Asian } \\
\hline & $\begin{array}{c}\text { Pem-cis } \\
(n=54) \\
n(\%)\end{array}$ & $\begin{array}{l}\text { Placebo-cis } \\
\qquad \begin{array}{c}n=53) \\
n(\%)\end{array}\end{array}$ & $P$-value & $\begin{array}{c}\text { Pem-cis } \\
(n=338) \\
n(\%)\end{array}$ & $\begin{array}{c}\text { Placebo-cis } \\
(n=332) \\
n(\%)\end{array}$ & $P$-value \\
\hline \multicolumn{7}{|l|}{ Laboratory } \\
\hline Neutropenia & $6(11)$ & $1(12)$ & 0.113 & $39(12)$ & $9(3)$ & $<0.001$ \\
\hline Anemia & $3(6)$ & $1(2)$ & 0.618 & $37(11)$ & $12(4)$ & $<0.001$ \\
\hline Leukopenia & $1(2)$ & $1(2)$ & $>0.999$ & $32(10)$ & $4(1)$ & $<0.001$ \\
\hline Thrombocytopenia & $2(4)$ & $1(2)$ & $>0.999$ & $13(4)$ & $5(2)$ & 0.092 \\
\hline \multicolumn{7}{|l|}{ Non-laboratory } \\
\hline Fatigue & $0(0)$ & $0(0)$ & NA & $19(6)$ & $7(2)$ & 0.026 \\
\hline Febrile neutropenia & $1(2)$ & $0(0)$ & $>0.999$ & $11(3)$ & $0(0)$ & 0.001 \\
\hline Nausea & $2(4)$ & $1(2)$ & $>0.999$ & $8(2)$ & $9(3)$ & 0.811 \\
\hline Vomiting & $0(0)$ & $2(2)$ & 0.243 & $8(2)$ & $8(2)$ & $>0.999$ \\
\hline Anorexia & $1(2)$ & $2(2)$ & 0.618 & $7(2)$ & $4(1)$ & 0.546 \\
\hline Diarrhea & $0(0)$ & $0(0)$ & NA & $5(2)$ & $0(0)$ & 0.062 \\
\hline Renal failure & $1(2)$ & $0(0)$ & $>0.999$ & $4(1)$ & $5(2)$ & 0.750 \\
\hline
\end{tabular}

${ }^{\dagger}$ Selection of grade 3 or 4 adverse events was based on those reported in Urba et al. ${ }^{12}$. Cis, cisplatin; $n$, number of patients with event; NA, not assessable; pem, pemetrexed.

These findings confirm that PS is a prognostic factor $^{12,26-28}$ and highlight the importance of PS as a reliable parameter that may be used as an inclusion criterion in clinical trials. PS has long been considered the most important prognostic factor for patients with SCCHN. A PS of 0 or 1 has been associated with a better OS in patients with advanced SCCHN. ${ }^{29}$ In a clinical trial involving patients with advanced SCCHN, response and survival were related to PS. ${ }^{30}$ In addition, the oral cavity, which is considered a poor prognostic factor, was the primary site of disease in both treatment arms in the EA, non-EA and global populations. ${ }^{12}$

In preplanned subgroup analyses involving all EA patients and EA patients in the ECOG PS 0 or 1 subgroups, OS and PFS seem to favor pemetrexed-cisplatin over placebo-cisplatin across most of the groups (all HR < 1.00), but the between-group differences were not statistically significant. Nonetheless, these differences may be potentially clinically relevant: it is possible that the small sample sizes explained the failure to achieve statistical significance.

The toxicity profile of pemetrexed-cisplatin in this subgroup analysis in the EA group did not show any unexpected toxicities. In the global ${ }^{12}$ and EA groups, drug-related grade 3 or 4 laboratory toxicities included neutropenia, anemia, thrombocytopenia and leukopenia. However, in contrast with the findings in the global population, ${ }^{12}$ the between-group differences in neutro- penia, anemia, and leukopenia in the EA group were not significant, possibly because the sample sizes were too small to achieve statistical significance. In contrast with the findings in the EA group, the incidence of anemia and fatigue was numerically higher and the betweentreatment group differences were statistically significant in the non-EA group, indicating that toxicity in SCCHN treatment may vary among patients of different ethnic origins. Nonetheless, the toxicity profile of pemetrexedcisplatin was consistent with the known toxicity profile in other tumor types. ${ }^{13,14}$

In conclusion, consistent with the findings in the global population, pemetrexed-cisplatin, as compared with placebo-cisplatin, did not improve survival for the EA group. Pemetrexed-cisplatin treatment led to improved OS in the EA group with an ECOG PS of 0 or 1 compared with placebo-cisplatin, but these results were not significant. However, the between-arm differences in OS and PFS were statistically significant in favor of pemetrexed-cisplatin in the global population with an ECOG PS of 0 or $1 .{ }^{12}$ In contrast with the findings in the global population, pemetrexed-cisplatin showed an OS advantage in EA patients who had received prior platinum-based therapy. ${ }^{12}$ Overall, the observations made in the EA group provide an insight in planning future global studies, especially patient selection, which is considered to be as important as the type of treatment selection. Although the various prognostic and 
disease-related factors are well balanced in the EA group relative to those in the overall population, ${ }^{12}$ caution should be used in interpreting the results of the EA subgroup analysis due to the underpowered, exploratory nature of these analyses.

\section{ACKNOWLEDGMENTS}

The retrospective analysis reported here and the original study were sponsored by Eli Lilly, Indianapolis, Indiana, USA. AMH, RC and MO are full-time employees of Eli Lilly. The authors thank Sharad Wankhade, Joseph Durrant and Angela Lorio for writing and editorial assistance. SW, JD and AL are full-time employees of PharmaNet-i3, inVentiv Health. The authors also thank Sedat Altug and Tuan Nguyen for reviewing the manuscript.

\section{REFERENCES}

1 Argiris A, Karamouzis MV, Raben D, Ferris RL. Head and neck cancer. Lancet 2008; 371: 1695-709.

2 Gold KA, Lee HY, Kim ES. Targeted therapies in squamous cell carcinoma of the head and neck. Cancer 2009; 115: 922-35.

3 Haddad RI, Shin DM. Recent advances in head and neck cancer. N Engl J Med 2008; 359: 1143-54.

4 Colevas AD. Chemotherapy options for patients with metastatic or recurrent squamous cell carcinoma of the head and neck. J Clin Oncol 2006; 24: 2644-52.

5 Clavel M, Vermorken JB, Cognetti F et al. Randomized comparison of cisplatin, methotrexate, bleomycin and vincristine $(\mathrm{CABO})$ versus cisplatin and 5 -fluorouracil $(\mathrm{CF})$ versus cisplatin $(\mathrm{C})$ in recurrent or metastatic squamous cell carcinoma of the head and neck. A phase III study of the EORTC Head and Neck Cancer Cooperative Group. Ann Oncol 1994; 5: 521-6.

6 Burtness B, Goldwasser MA, Flood W, Mattar B, Forastiere AA, Eastern Cooperative Oncology Group. Phase III randomized trial of cisplatin plus placebo compared with cisplatin plus cetuximab in metastatic/recurrent head and neck cancer: an Eastern Cooperative Oncology Group study. J Clin Oncol 2005; 23: 8646-54.

7 Gibson MK, Li Y, Murphy B et al. Randomized phase III evaluation of cisplatin plus fluorouracil versus cisplatin plus paclitaxel in advanced head and neck cancer (E1395): an intergroup trial of the Eastern Cooperative Oncology Group. J Clin Oncol 2005; 23: 3562-7.

8 Taylor EC, Kuhnt D, Shih Cet al. A dideazatetrahydrofolate analogue lacking a chiral center at C-6, N-[4-[2-(2-amino3,4-dihydro-4-oxo-7H-pyrrolo[2,3-d]pyrimidin-5-yl)ethyl] benzoyl]-L-glutamic acid, is an inhibitor of thymidylate synthase. J Med Chem 1992; 35: 4450-4.
9 Schultz RM, Patel VF, Worzalla JF, Shih C. Role of thymidylate synthase in the antitumor activity of the multitargeted antifolate, LY231514. Anticancer Res 1999; 19: 437-43.

10 Shih C, Habeck LL, Mendelsohn LG, Chen VJ, Schultz RM. Multiple folate enzyme inhibition: mechanism of a novel pyrrolopyrimidine-based antifolate LY231514 (MTA). Adv Enzyme Regul 1998; 38: 135-52.

11 Pivot X, Raymond E, Laguerre B et al. Pemetrexed disodium in recurrent locally advanced or metastatic squamous cell carcinoma of the head and neck. Br J Cancer 2001; 85: 649-55.

12 Urba S, van Herpen CM, Sahoo TP et al. Pemetrexed in combination with cisplatin versus cisplatin monotherapy in patients with recurrent or metastatic head and neck cancer: final results of a randomized, double-blind, placebocontrolled, phase 3 study. Cancer 2012; 118: 4694-705.

13 Vogelzang NJ, Rusthoven JJ, Symanowski J et al. Phase III study of pemetrexed in combination with cisplatin versus cisplatin alone in patients with malignant pleural mesothelioma. J Clin Oncol 2003; 21: 2636-44.

14 Scagliotti GV, Parikh P, von Pawel J et al. Phase III study comparing cisplatin plus gemcitabine with cisplatin plus pemetrexed in chemotherapy-naive patients with advancedstage non-small-cell lung cancer. J Clin Oncol 2008; 26: 3543-51.

15 Ahn MJ, Yang JC, Liang J et al. Randomized phase II trial of first-line treatment with pemetrexed-cisplatin, followed sequentially by gefitinib or pemetrexed, in East Asian, never-smoker patients with advanced non-small cell lung cancer. Lung Cancer 2012; 77: 346-52.

16 Yang CH, Simms L, Park K, Lee JS, Scagliotti G, Orlando M. Efficacy and safety of cisplatin/pemetrexed versus cisplatin/gemcitabine as first-line treatment in East Asian patients with advanced non-small cell lung cancer: results of an exploratory subgroup analysis of a phase III trial. J Thorac Oncol 2010; 5: 688-95.

17 Belani CP, Wu YL, Chen YM et al. Efficacy and safety of pemetrexed maintenance therapy versus best supportive care in patients from East Asia with advanced, nonsquamous non-small cell lung cancer: an exploratory subgroup analysis of a global, randomized, phase 3 clinical trial. J Thorac Oncol 2012; 7: 567-73.

18 Auluck A, Hislop G, Bajdik C, Poh C, Zhang L, Rosin M. Trends in oropharyngeal and oral cavity cancer incidence of human papillomavirus (HPV)-related and HPV-unrelated sites in a multicultural population: the British Columbia experience. Cancer 2010; 116: 2635-44.

19 Warnakulasuriya S. Global epidemiology of oral and oropharyngeal cancer. Oral Oncol 2009; 45: 309-16.

20 Liao CT, Chang JT, Wang HM et al. Analysis of risk factors of predictive local tumor control in oral cavity cancer. Ann Surg Oncol 2008; 15: 915-22.

21 Ho PS, Ko YC, Yang YH, Shieh TY, Tsai CC. The incidence of oropharyngeal cancer in Taiwan: an endemic 
betel quid chewing area. J Oral Pathol Med 2002; 31: 213-19.

22 Therasse P, Arbuck SG, Eisenhauer EA et al. New guidelines to evaluate the response to treatment in solid tumors. European Organization for Research and Treatment of Cancer, National Cancer Institute of the United States, National Cancer Institute of Canada. J Natl Cancer Inst 2000; 92: 205-16.

23 National Cancer Institute. Common Terminology Criteria for Adverse Events, vers. 3.0 [published 9 Aug 2006]. [updated 15 December 2012 cited 20 December 2012 ]. Available from: http://ctep.cancer.gov/protocol Development/electronic_applications/docs/ctcaev3.pdf.

24 Kaplan EL, Meier P. Nonparametric estimation of incomplete observations. J Am Stat Assoc 1958; 53: 457-81.

25 Cox DR. Regression models and life-tables (with discussion). J R Stat Soc Ser B Stat Methodol 1972; 34: 187220.
26 Conill C, Verger E, Salamero M. Performance status assessment in cancer patients. Cancer 1990; 65: 1864-6.

27 Sørensen JB, Klee M, Palshof T, Hansen HH. Performance status assessment in cancer patients. An inter-observer variability study. Br J Cancer 1993; 67: 773-5.

28 Vermorken JB, Mesia R, Rivera F et al. Platinum-based chemotherapy plus cetuximab in head and neck cancer. $N$ Engl J Med 2008; 359: 1116-27.

29 Forastiere AA, Metch B, Schuller DE et al. Randomized comparison of cisplatin plus fluorouracil and carboplatin plus fluorouracil versus methotrexate in advanced squamous-cell carcinoma of the head and neck: a Southwest Oncology Group study. J Clin Oncol 1992; 10: 1245-51.

30 Jacobs C, Lyman G, Velez-García E et al. A phase III randomized study comparing cisplatin and fluorouracil as single agents and in combination for advanced squamous cell carcinoma of the head and neck. J Clin Oncol 1992; 10: 257-63. 